\title{
Electron Microprobe Analysis and Tissue Reaction around Titanium Alloy Spinal Implants
}

\author{
Hee-Dong Kim, Ki-Soo Kim, Sung-Chan Ki, Yong-Soo Choi \\ Department of Orthopedic Surgery, Kwangju Christian Hospital, Gwangju, Korea
}

\begin{abstract}
Study Design: A retrospective study of tissue surrounding titanium alloy spinal implants was performed using histological and electron microprobe analysis.

Purpose: To identify the metal debris generated by spinal implants, and then to evaluate the electron microprobe analysis results and the histological response of soft tissue surrounding the spinal implants.

Overview of Literature: Microscopic metal particles from the soft tissue surrounding joint arthroplasty have been shown to activate a macrophage response that leads to bone resorption and increased inflammation. The effect of unintended wear particles in spinal instrumentation remains a clinical concern.

Methods: Ten patients (average age, 51.3 years), 6 men and 4 women, who had undergone previous lumbar fusions using pedicle screw instrumentation and who were now undergoing revision surgery were included in the study. The tissues obtained from the adjacent area of these implants were analyzed by light microscopy, immunohistochemistry and scanning electron microscope. After the removing the spinal implants, the changes of back pain and the spinal fusion were assessed.

Results: There were metal particles in the soft tissue in 7 cases. Histological finding observed mild chronic inflammation surrounding the deposition of the metal particles and the anti Cotrel-Dubousset 68 positive macrophages were observed at tissue adjacent to the metal particles in 5 patients. Scanning electron microscopy of the specimens showed metallic debris within the tissue and mapping of the metallic particles revealed the distribution of titanium in the tissue in 5 cases. Nine patients had successful relief of back pain after removing the spinal implants. Improvement of the back pain may be an association macrophage response rather than the metal particle.

Conclusions: The presence of metallic particles generated from spinal implants may serve as the impetus for a late-onset inflammatory response and late operative site pain.
\end{abstract}

Key Words: Posterior pedicular instrumentations, Titanium alloy, Metallic debris, Tissue reaction

\section{Introduction}

The clinical outcomes of the side effects caused by metal debris generated from the micromotion of orthopedic implants have been reported ${ }^{1-4}$, and the use of metal instrumentation, particularly titanium, for spinal fusion has introduced the possibility of generating microscopic metal particles that may be deposited in either the paraspinal soft tis- sues or on the neural elements ${ }^{5-11}$.

Dubousset et al. ${ }^{7}$ reported late complications in 18 patients managed with posterior stainless steel CotrelDubousset (CD) instrumentation with an average follow-up of 34 months after instrumentation. Histopathology revealed acute and chronic inflammation with granuloma formation at the instrumentation transverse connector site, which necessitated the removal of the instrumentation. The etiology of this complication was considered to be a sterile

Corresponding author: Yong-Soo Choi, MD

Department of Orthopedic Surgery, Kwangju Christian Hospital

264 Yangrim-dong, Nam-gu, Gwangju, 503-040, Korea

Tel: +82-62-650-5062, Fax: +82-62-650-5066, E-mail: stemcellchoi@yahoo.co.kr 
inflammatory reaction secondary to fretting corrosion of the instrumentation. Wang et al. ${ }^{12}$ reported metal debris associated with the use of titanium implants in nine patients. It was observed that wear debris is generated by the use of titanium spinal instrumentation in patients with pseudarthrosis, and these particles activate a similar macrophage cellular response in the spinal tissues to that observed in the surrounding joint prostheses. Kasai et al. ${ }^{13}$ reported that approximately one third of patients with titanium alloy spinal implants exhibited abnormal serum or hair metal concentrations at a mean time of 5.1 years after surgery and that titanium or aluminum may travel to distant organs after dissolution of metals from the spinal implants.

Microscopic metal particles from the soft tissue surrounding joint arthroplasty have been shown to activate a

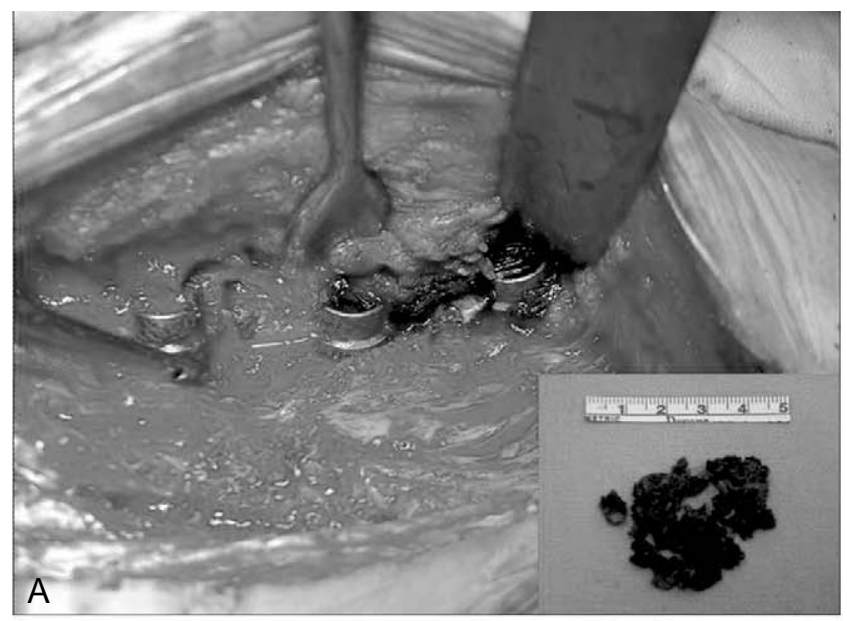

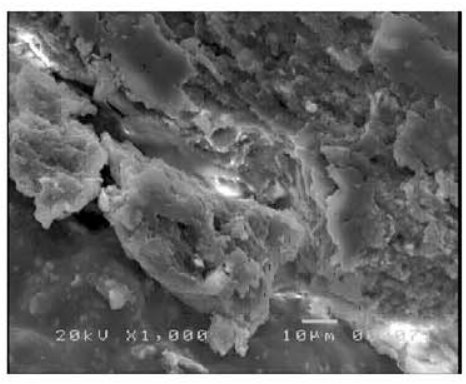

SEM of Particles
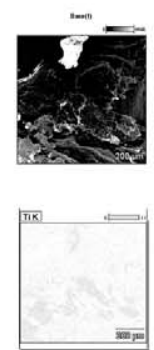

Mapping of Particles

\section{C}
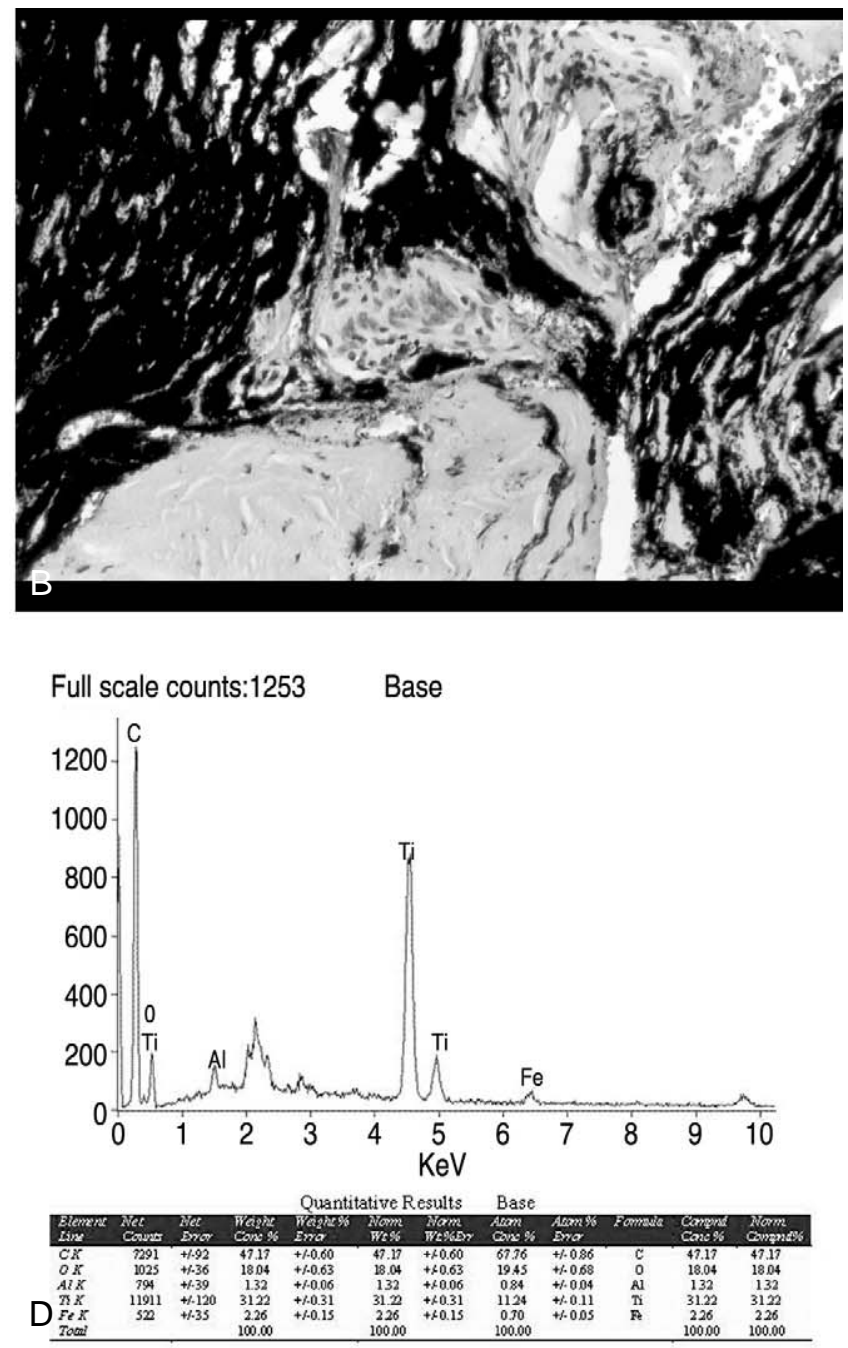

Fig. 1. (A) Operative finding shows local discolorization of the soft tissues around spinal implant (Case 2). (B) Histologic finding reveals obvious metallosis with black staining of the tissue. (C) Scanning electron microscopy view of specimen shows the metallic debris within tissue $(\times 1,000)$ and mapping of the metallic particles shows the distributions of the titanium in the tissue. (D) Quantitative analysis of the metallic debris of specimen was done with energy dispersive X-ray spectrometer. 
(average age, 51.3 years), who underwent revision surgery from January 2000 to May 2005 at the Kwangju Christian Hospital after having undergone a previous lumbar decompression and fusion with titanium pedicle screw instrumentation, including 6 Diapason instrumentation cases, 3 Trifix instrumentation cases, and $1 \mathrm{Xia}$ instrumentation case. The reason for the revision surgery was hardware removal for back pain without any specific cause in 2 cases and abnormal radiological findings in 8 cases, including periosteal reaction surrounding the pedicle screw in 5 cases, screw breakage in 3 cases, and 1 case of rod failure (Table 1). None of these patients had been identified with draining sinuses or clinical and/or laboratory signs of infection at any time after implantation.

Soft tissue samples were obtained for light microscopic and scanning electron microscopic evaluation. At the time of surgery, soft tissue samples were taken from the dark brown or black discolored area macroscopically surrounding the deposition of metal particles released in the soft tissues ( 7 cases, Fig. 1A) and from the pseudomembrane in the vicinity of the connection area of the metal rods and screws in 3 cases. All the specimens were cultured for the possibility of a subclinical infection. For the light microscopy evaluation, all the specimens were fixed in $10 \%$ buffered formalin, and processed using routine light microscope techniques (embedded in paraffin, cut in $5 \mu \mathrm{m}$ slices, and stained with hematoxylin-eosin). The specimens were also examined for debris-induced effects on the soft tissue surrounding the deposition of the metal particles. Under a light microscope, the tissue was evaluated for any acute and chronic inflammation as well as for a histiocytic and foreign-body giant-cell reaction. The macrophages were identified by immunostaining the sections with the anti-CD 68 macrophage marker (Dako) using an indirect immunoperoxidase technique. The positive cells were stained immunologically with a red color using the Avidin-biotin complex method.

For the scanning electron microscopy (SEM) examination in 7 cases, the specimens were fixed in $2 \%$ glutaraldehyde in a phosphate buffer and were post fixed with $1 \%$ osmium tetroxide in the same buffer and embedded in araldite. The specimens provided as a sample were cut to a size of $1 \times 1$ $\times 1 \mathrm{~mm}$, freeze-dried for 8 hours, and subsequently coated with gold (Au) for 30 seconds. The metal debris was examined and photographed by SEM at an acceleration voltage of $20 \mathrm{kV}$ (JSM 5400; JEOL Co., Tokyo, Japan). In addition, the composition distribution obtained from the SEM images

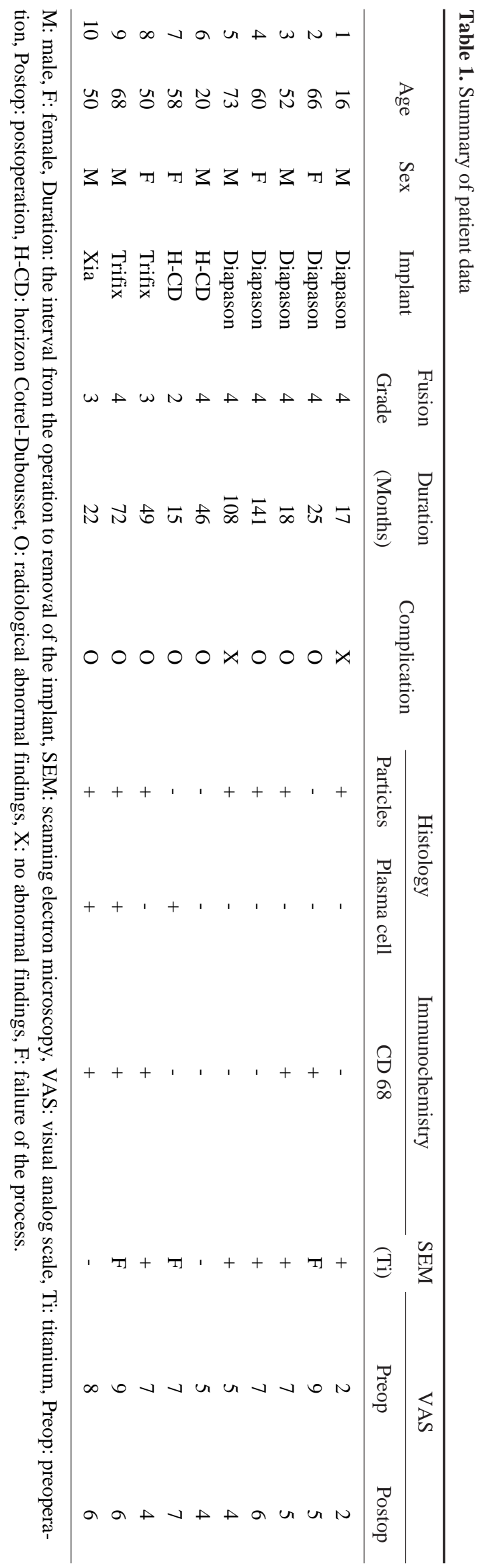


was analyzed by elemental mapping (Fig. 1C). Electron dispersion X-ray analysis of the particles within the selected samples was performed to confirm the presence of metal particles in cellular samples (Fig. 1D).

After removing the spinal implants, the changes of back pain were evaluated by visual analog scale (VAS) scores and the assessment of spinal fusion was done according to Lenke's ${ }^{14}$ criteria.

The associations between metal particles and implants, complications such as radiological abnormal findings, antiCD 68 marker, the changes of back pain using the visual analog scale were assessed with the Mann-Whitney U-test. The histological anti-CD 68 marker was examined to determine if it was associated with the changes of back pain. All the data were compared statistically using the Mann-Whitney test. A $p$ value $<0.05$ was considered significant.

\section{Results}

Ten patients were enrolled in the study. Eight patients had radiologically abnormal findings such as a periosteal reaction surrounding the pedicle screw and a screw or rod failure. Two patients in the study had late operative site pain without any radiological problems. All cultures taken intraoperatively were negative. Local discoloration of the soft tissues around metal-metal junctions was observed (Fig. 1A, Case 2), and when the metal was examined after explantation, discoloration at the screw-rod junction was identified in 7 cases. Of the 10 patients, 9 (90\%) showed successful relief of back pain after removing the spinal implants. The average VAS scores improved from 6.6 prior to removal, to an average of 4.9 at the last follow-up (mean follow-up after removing spinal implants: 17 months). Radiographic fusion success according to Lenke's criteria was demonstrated in 9 cases. The radiographic fusion pattern was as follows: definitely solid in 7 cases, possibly solid in 2 cases and probably not solid in 1 case. One case complained of persistent back pain (VAS; 7) with pseudoarthrosis. Radiographic findings revealed screw breakage and pseuoarthrosis. The author recommended treatment for pseudoarthrosis but the patient rejected any further procedures except for the removal of the spinal implant.

There was obvious metallosis with black staining of the internal membrane of the tissue around the spinal implant in 7 cases (Fig. 1B). Histological finding observed mild chronic inflammation surrounding the deposition of the metal particles such as plasma cells in 3 patients and lymphocyte cuff in 2 patients. There was no acute inflammation in these specimens. The anti CD 68 positive macrophages were observed at tissue adjacent to the metal particles in 5 patients (Fig. 2, Case 5) in contrast to stainless steel implants ${ }^{8}$. We did not verify a positive association between the deposition of the metal particles and anti-CD 68 macrophage marker.

SEM of the specimen showed metallic debris within the tissue, and elemental mapping of the metallic particles showed titanium distributed in the tissue of 5 cases (Fig. 1C). Electron dispersion $\mathrm{X}$-ray analysis showed that the black particles forming clusters were rich in titanium (Fig. 1D).
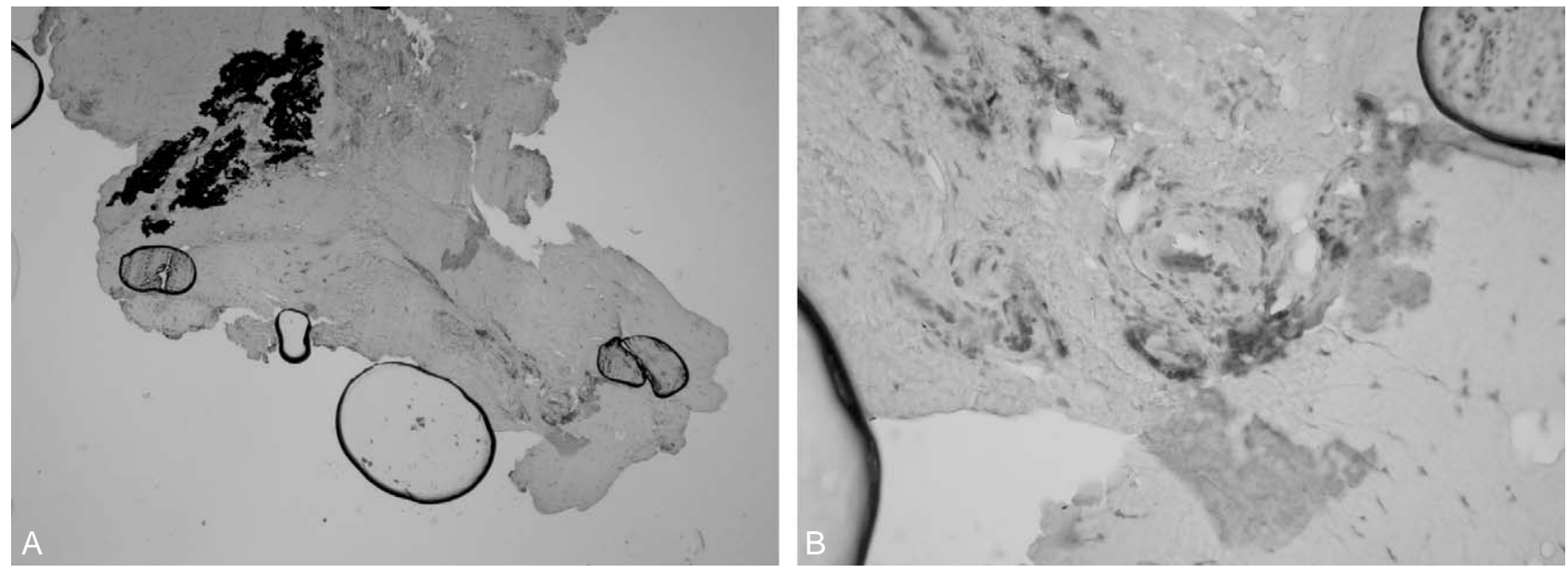

Fig. 2. (A) Metallic debris was identified in the dense connective tissue and the anti Cotrel-Dubousset 68 positive macrophages were observed at tissue adjacent to the metal particles (Avidin-biotin complex, $\times 100)$. (B) Macrophages as stained positive by anti CD 68 marker (Avidin-biotin complex, $\times 200$, Case 5). 
Comparison of radiological complications and metal particles showed no significant differences in the generation of the metal particles $(\mathrm{p}=0.30)$. There were no statistically significant differences in the association between metal particles and anti-CD 68 marker as well as the association between metal particles and the visual analog scale $(p>0.05)$. The occurrence of the metal particles was unrelated to radiological abnormal findings ( $p>0.05$ ) (Table 2). Comparison of the anti-CD 68 positive group $(\mathrm{n}=5)$ and the anti-CD 68 negative group $(\mathrm{n}=5)$ showed significant difference in back pain preoperatively $(\mathrm{p}=0.025)$ and no difference in back pain postoperatively $(\mathrm{p}=0.545)$ using the Mann-Whitney U-test (Table 3). Improvement of back pain may be associated with macrophage response rather than the metal particles.

\section{Discussion}

Titanium alloy, containing approximately $90 \%$ titanium, $6 \%$ aluminum, and $4 \%$ vanadium, is a light and strong metallic material that is highly biocompatible and commonly used in orthopedic practice ${ }^{15,16}$. Titanium is generally regarded as safe for an organism. However, it has been reported that titanium has the biochemical activity of increasing the prostaglandin E2 or interleukin- $1^{17,18}$. Titanium is known to wear out easily, and may cause localized problems in the tissues surrounding the implants, or travel to distant organs and cause systemic problems ${ }^{19,20}$.

Metallic particles from titanium alloy spinal implants were examined metallurgically and histologically in this study. Metallic particles were found abundantly around the intact screw-rod interface, as well as at the site of the screw or rod failure. SEM of the specimen showed metallic debris within the tissue, and mapping of the metallic particles showed titanium distributed in the tissue in 5 cases. The results of immunohistochemical staining revealed macrophages to be mainly present in the soft tissues adjacent to the metal particles. No signs suggesting an allergic reaction or infection were found on histological examination. These findings show that titanium particles had been generated by the titanium-alloy pedicle screw constructs and deposited in the soft tissue immediately surrounding the instrumentation, and the reaction against the metallic particles was manifested by the migration of macrophages to the involved area. A review of the joint prosthesis literature revealed articles describing local tissue reaction to metallic wear debris ${ }^{21-24}$, as well as in vitro human macrophage response to retrieved titanium alloy particles ${ }^{25,26}$. According to Wang et al. ${ }^{12}$, metallic particles from titanium alloy spinal implants activated a macrophage cellular response in the spinal tissues similar to that observed in joint prostheses. A number of other retrospective clinical studies have documented an inflammatory, foreign-body reaction in the soft

Table 2. Statistical analysis for histological metal particles

\begin{tabular}{lccc}
\hline & $\begin{array}{c}\text { Particles } \\
(+)\end{array}$ & $\begin{array}{c}\text { Particles } \\
(\mathrm{n}=7)\end{array}$ & p-value \\
$(\mathrm{n}=3)$ & & \\
\hline Implant & & & 0.500 \\
$\quad$ Diapason (n=5) & $4(80)$ & $2(20)$ & 0.301 \\
$\quad$ Non-Diapason (n=5) & $3(60)$ & $3(100)$ & 0.500 \\
Complication (+) & $5(71.4)$ & $1(33.3)$ & 0.813 \\
CD 68(+) & $4(57.1)$ & $17.5(5.8)$ & 0.639 \\
VAS (preoperation) & $37.5(5.3)$ & $18.5(6.2)$ & \\
VAS (postoperation) & $36.5(5.2)$ & & \\
\hline
\end{tabular}

VAS: visual analog scale, Mann-whitney U-test.

Table 3. Statistical comparision of anti-CD 68 marker and back

\begin{tabular}{lcccc}
\hline & CD 68 & N & Mean & p-value \\
\hline VAS_pre & $(-)$ & 5 & $5.2 \pm 0.92$ & 0.025 \\
& $(+)$ & 5 & $8.0 \pm 0.45$ & \\
VAS_post & $(-)$ & 5 & $4.6 \pm 0.87$ & 0.545 \\
& $(+)$ & 5 & $5.2 \pm 0.37$ & \\
\hline
\end{tabular}

VAS_pre: preoperative visual analog scale, VAS_post: postoperative visual analog scale. 
tissue structures adjacent to spinal implants ${ }^{27-30}$. Cook et al. ${ }^{6}$ reported that late operative site pain is most likely caused by local soft tissue reaction to the implants, and late operative site pain of no apparent cause after posterior instrumentation of scoliosis is a distinct clinical entity and is relieved by implant removal in most patients. This study demonstrated that 9 patients (90\%) had successful relief of their back pain after removing spinal implants.

Limitations of this study include relatively small material samples, limited cases ${ }^{10}$, and the lack of a control group. Also, it was assumed that metal particles were continuously generated from micromotion or macromotion between the titanium-alloy pedicle screw construct junctions for the duration of implantation. Metallic particles from titanium alloy spinal implants could activate a macrophage cellular response that might have deleterious effects on the fusion mass, spinal tissues, and neural elements. Because the effects of metal particles on the local and systemic tissues are still unknown, further investigation is needed to clarify the toxicological importance of metal particles generated from titanium alloy spinal implants.

\section{Conclusions}

Titanium particles were generated by titanium-alloy pedicle screw constructs and deposited in the soft tissue immediately surrounding the instrumentation. The presence of metallic particles released from the titanium alloy spinal implants might serve as the impetus for late-onset inflammatory response and late operative site pain.

\section{REFERENCES}

1. Hallab N, Merrit K, Jacobs JJ: Metal sensitivity in patients with orthopaedic implants. J Bone Joint Surg Am 2001; 83A: 428-436.

2. Jacobs JJ, Gilbert JL, Urban RM: Corrosion of metal orthopaedic implants. J Bone Joint Surg Am 1998; 80: 268282.

3. Mak KH, Wong TK, Poddar NC: Wear debris from total hip arthroplasty presenting as an intrapelvic mass. J Arthroplasty 2001; 16: 674-676.

4. Tharani R, Doray FJ, Schmalzried TP: The risk of cancer following total hip or knee arthroplasty. J Bone Joint Surg Am 2001; 83A: 774-780.
5. Aydinli U, Karaeminogullari O, Tiskaya K: Postoperative deep wound infection in instrumented spinal surgery. Acta Orthop Belg 1999; 65: 182-187.

6. Cook S, Asher M, Lai SM, Shobe J: Reoperation after primary posterior instrumentation and fusion for idiopathic scoliosis: toward defining late operative site pain of unknown cause. Spine 2000; 25: 463-468.

7. Dubousset J, Schuffleberger HL, Wenger D: Late "infection" with CD instrumentation. Orthop Trans 1994; 18: 121-124.

8. Hallab NJ, Cunningham BW, Jacobs JJ: Spinal implant debris-induced osteolysis. Spine 2003; 28: S125-138.

9. Mody DR, Esses SI, Heggeness MH: A histologic study of soft-tissue reaction to spinal implants. Spine 1994; 19: 1153-1156.

10. Senaran H, Atilla P, Kaymaz F, Acaroglu E, Surat A: Ultrastructural analysis of metallic debris and tissue reaction around spinal implants in patients with late operative site pain. Spine 2004; 29: 1618-1623.

11. Viola RW, King HA, Adler SM, Wilson CB: Delayed infection after elective spinal instrumentation and fusion: a retrospective analysis of eight cases. Spine 1997; 22: 24442450.

12. Wang JC, Yu WD, Sandhu HS, Betts F, Bhuta S, Delamarter RB: Metal debris from titanium spinal implants. Spine 1999; 24: 899-903.

13. Kasai Y, Iida R, Uchida A: Metal concentrations in the serum and hair of patients with titanium alloy spinal implants. Spine 2003; 28: 1320-1326.

14. Lenke LG, Prridwell KH, Bullis D, et al: Results of in site fusion for isthmic spondylolisthesis. J Spinal Disord 1992; 5: 433-442.

15. Head WC, Bauk DJ, Emerson RH Jr: Titanium as the material of choice for cementless femoral components in total hip arthroplasty. Clin Orthop Relat Res 1995; 311: 8590.

16. Rocca M, Fini M, Giavaresi G, Nicoli Aldini N, Giardin R: Tibial implants: biomechanicaland histomorphometric studies of hydroxyapatite-coated and uncoated stainless steel an titanium screws in long-term ovariectomized sheep. Int J Artif Organs 2001; 24: 649-654.

17. Granchi D, Verri E, Ciapetti G, et al: Bone-resorbing cytokines in serum of patients with aseptic loosening of hip prostheses. J Bone Joint Surg Br 1998; 80: 912-917.

18. Tsutsui T, Kawaguchi H, Fujino A, Sakai A, Kaji H, Nakamura T: Exposure of macrophage-like cells to titanium particles does not affect bone resorption, but inhibits 
bone formation. J Orthop Sci 1999; 4: 32-38.

19. Haynes DR, Rogers SD, Hay S, Pearcy MJ, Howie DW: The differences in toxicity and release of bone-resorbing mediators induced by titanium and cobalt-chromium alloy wear particles. J Bone Joint Surg Am 1993; 75: 825-834.

20. Brayda-Bruno M, Fini M, Pierini G, Giavaresi G, Rocca M, Giardino R: Evaluation of systemic metal diffusion after spinal pedicular fixation with titanium alloy and stainless steel system: a 36-month experimental study in sheep. Int J Artif Organs 2001; 24: 41-49.

21. Doorn PF, Campbell PA, Amstutz HC: Metal versus polyethylene wear particles in total hip replacements. A review. Clin Orthop Relat Res 1996; 329: S206-216.

22. Doorn PF, Mirra JM, Campbell PA, Amstutz HC: Tissue reaction to metal on metal total hip prostheses. Clin Orthop Relat Res 1996; 329: S187-205.

23. La Budde JK, Orosz JF, Bonfiglio TA, Pellegrini VD Jr: Particulate titanium and cobalt-chrome metallic debris in failed total knee arthroplasty. A quantitative histologic analysis. J Arthroplasty 1994; 9: 291-304.

24. Witt JD, Swann M: Metal wear and tissue response in failed titanium alloy total hip replacements. J Bone Joint
Surg Br 1991; 73: 559-563.

25. Lee SH, Brennan FR, Jacobs JJ, Urban RM, Ragasa DR, Glant TT: Human monocyte/ macrophage response to cobalt-chromium corrosion products and titanium particles in patients with total joint replacements. J Orthop Res 1997; 15: 40-49.

26. Maloney WJ, James RE, Smith RL: Human macrophage response to retrieved titanium alloy particles in vitro. Clin Orthop Relat Res 1996; 322: 268-278.

27. Aydinli U, Karaeminogullari O, Tiskaya K: Postoperative deep wound infection in instrumented spinal surgery. Acta Orthop Belg 1999; 65: 182-187.

28. Gaine WJ, Andrew SM, Chadwick P, Cooke E, Williamson JB: Late operative site pain with isola posterior instrumentation requiring implant removal: infection or metal reaction? Spine 2001; 26: 583-587.

29. Mody DR, Esses SI, Heggeness MH: A histologic study of soft-tissue reactions to spinal implants. Spine 1994: 19: 1153-1156.

30. Xu R, Ebraheim NA, Nadaud MC, Phillips ER: Local tissue of the lumbar spine response to titanium plate-screw system. Case reports. Spine 1996; 21: 871-873. 